\title{
A promoção da cooperação nos consórcios intermunicipais de saúde do estado do Paraná
}

\author{
Willson Gerigk \\ Universidade Estadual do Centro-Oeste (Unicentro/PR) \\ Huáscar Fialho Pessali* \\ Universidade Federal do Paraná (UFPR)
}

\begin{abstract}
Os consórcios intermunicipais de saúde (CIS) são hoje instituições públicas disseminadas. A descentralização promovida na área de saúde nos anos 1990 estimulou a aglutinação de municípios, em especial os menores, para enfrentar uma dificuldade comum - a prestação de serviços especializados. São vinculados a algum CIS $41 \%$ dos municípios do país. Se considerarmos apenas os municípios com até 20 mil habitantes, $76 \%$ deles têm tal vínculo. Os CIS tentam fortalecer a cooperação entre os municípios e assim viabilizar parte de suas políticas públicas na área de saúde. O objetivo desta pesquisa é verificar, através de um survey com seus diretores, como se lida com conflitos e se promove a cooperação nos CIS paranaenses. Os resultados indicam que há atratividade financeira para participação nos CIS; valoriza-se o consenso entre os membros; há grande tolerância ao comportamento desviante; e a retaliação não cooperativa é rara e menos intensa do que a ação inicial.
\end{abstract}

Palavras-chave: cooperação; consórcio público; consórcio intermunicipal de saúde; estado do Paraná.

La promoción de la cooperación en los consorcios intermunicipales de salud en el estado de Paraná

Los consorcios intermunicipales de salud (CIS) son hoy instituciones públicas difundidas. La descentralización promovida en la salud en la década de 1990 estimuló la agregación de municipios, especialmente los más pequeños, para hacer frente a un desafío común - la prestación de servicios especializados. Está vinculada a algún CIS 41\% de los municipios del país, principalmente (76\%) aquellos con menos de 20 mil habitantes. Los CIS tratan de establecer una cooperación entre los municipios y por lo tanto permite realizar parte de sus políticas públicas de salud. El objetivo de la investigación es verificar,

DOI: http://dx.doi.org/10.1590/0034-76121779

Artigo recebido em 11 nov. 2013 e aceito em 24 jul. 2014.

* O autor agradece o apoio do CNPq (Processo PQ 306568/2012-8).

Rev. Adm. Pública - Rio de Janeiro 48(6):1525-1543, nov./dez. 2014 
desde el punto de vista de los administradores, cómo los CIS en Paraná hacen frente a los conflictos y promueven la cooperación. Los resultados indican que existen atractivos financieros para la participación en los CIS, el consenso entre los miembros é valorado, hay gran tolerancia a la conducta desviada, y la represalia no cooperativa es rara.

Palabras clave: cooperación; consorcio público; consorcio intermunicipal de salud; estado de Paraná.

The promotion of cooperation in healthcare consortia in Paraná, Brazil

Healthcare consortia (CIS) are public institutions that have become widely spread. This stems from the decentralization promoted in the national health care system in the 1990s, pushing smaller municipalities to face a common challenge - the provision of specialized health services. About $41 \%$ of all municipalities in Brazil take part in a CIS, of which $76 \%$ have up to twenty thousand inhabitants. Through the promotion of cooperation among members, CIS carry out part of its public policies in the health area. The aim of this research is to verify, through a survey with CIS' managers, how they deal with conflicts and how cooperation is promoted by CIS in Paraná State. Results indicate that there is financial attractiveness for participation in CIS; members value consensus over majority decisions; and retaliation to defection is rare and less intense.

KEYWORDs: cooperation; public consortium; inter-municipal healthcare consortium; Paraná State.

\section{Introdução}

Nas últimas duas décadas houve significativo aumento da complexidade e dos campos de aplicação dos serviços de saúde. Isso veio acompanhado da descentralização federativa das responsabilidades em sua prestação. A baixa alavancagem financeira de boa parte dos municípios brasileiros, porém, foi uma dificuldade que os pressionou a buscar saídas conjuntas. São exemplos disso a formação, a institucionalização e o fortalecimento dos consórcios intermunicipais de saúde (CIS). Os CIS foram imaginados como institucionalidades que conjugam os entes municipais para viabilizar o acesso de seus munícipes ao atendimento especializado na área de saúde.

A descentralização promovida pela regulamentação do Sistema Único de Saúde (SUS) a partir da Constituição Federal de 1988, das Leis Orgânicas da Saúde e das Normas Operacionais do Ministério da Saúde exigiu dos municípios do interior uma maior participação nas ações de saúde (Neves, 2001). Ao mesmo tempo, os estados perderam parte de suas funções executivas e deixaram lacunas na organização de sistemas regionais hierarquizados. Os municípios viram assim a necessidade de interagir mais ativamente a fim de complementar seus recursos e estruturas, viabilizar atendimento ambulatorial e hospitalar de maior complexidade, e resolver problemas de recursos humanos e financeiros para prover acesso aos serviços de saúde a um maior número de pessoas (Lima, 2000).

Os CIS aparecem nesse cenário como uma institucionalidade criada para lidar com tais dificuldades e ajudar a efetivar um modelo mais viável de regionalização (Neves e Ribei- 
ro, 2006). Eles representam parcerias entre governos municipais, geralmente vizinhos, que pactuam regras de financiamento de serviços e de acesso de clientelas com base em recursos compartilhados (Ribeiro e Costa, 2000). Em alguns casos, os estados e a União também participam. Nicoletto e colaboradores (2005) salientam que os CIS potencializam a assistência médica especializada de forma regionalmente distribuída. Assim, os consórcios intermunicipais têm se tornado um arranjo disseminado de governança regional na área da saúde, sendo inclusive levados para outras áreas (Ipea, 2010), como se viu com a promulgação da Lei Federal no 11.107/2005 (Brasil, 2005).

As pesquisas sobre os CIS em boa parte se voltam a analisar sua estrutura de funcionamento, sua forma de gestão, aspectos da oferta de assistência médica especializada por eles viabilizada, benefícios gerados aos consorciados e satisfação dos usuários (Junqueira et al., 1999; Lima, 2000; Ribeiro e Costa, 2000; Schneider, 2001; Nicoletto et al., 2005; Neves e Ribeiro, 2006; Oliveira, 2008; Muller e Greco, 2010). Este estudo objetiva incluir um aspecto às pesquisas em voga, qual seja, identificar a percepção dos diretores dos consórcios sobre o papel e a dinâmica da cooperação nos CIS. Isso foi feito através de consulta aos diretores dos CIS do estado do Paraná.

A seção 2 apresenta a motivação e a fundamentação teórica do estudo acerca da cooperação. A seção 3 apresenta um histórico e um dimensionamento dos consórcios públicos brasileiros e dos CIS. A seção 4 explica a metodologia aplicada na pesquisa, enquanto a seção 5 discute os principais resultados. A seção 6 conclui o trabalho.

\section{Cooperação}

Nas ciências sociais, situações em que o retorno de uma ação individual depende das ações de outros são tratadas como dilemas sociais ou problemas de ação coletiva (Ostrom, 1990). Ao longo do século XX, muitas das recomendações e formulações institucionais para superá-los sugeriam o incentivo à competição entre atores individuais (em geral privados) ou a hierarquia completa (em geral do Estado). Viu-se, porém, que muitas dessas soluções não puderam ser implementadas ou, se tentadas, não foram satisfatórias (Fong et al., 2005). Isso chamou atenção para situações em que uma saída diferente das duas receitas tradicionais foi encontrada (Bowles, 2004). Robert Keohane e Elinor Ostrom (1995) identificaram em tais situações o desenho de sistemas policêntricos de governança. Esses sistemas podem conter a participação de autoridades centrais ou instâncias superiores de governos orientando e patrocinando modelos amplos de políticas e estruturas que são então complementados por atores locais ou instâncias menores de governo (Pessali, 2011).

Desenhar instituições que promovam a cooperação, como salienta Elinor Ostrom (2005), não é tarefa trivial. Robert Axelrod (1986), em um célebre estudo sobre as origens da cooperação e os elementos que a sustentam, propôs ações que podem ajudar em tal tarefa. Suas propostas consideram situações em que os atores pensam de forma egoísta e há conflitos de interesse - a ação individual de um ator pode causar danos ao outro se não for cooperativa. As propostas, entretanto, podem ser ainda mais potentes em situações não tão extremas. 
A cooperação mútua pode ser promovida em três frentes: 1) incrementar a importância do futuro em relação ao presente; 2) modificar os retornos atribuídos aos agentes; e 3) ensinar aos agentes valores e diretrizes que sirvam para promover a cooperação. Baseando-se nesses níveis, cinco formas de promover a cooperação são vislumbradas: a) ampliar as projeções sobre o futuro; b) criar incentivos e penalizações; c) ensinar os atores a se preocuparem uns com os outros; d) ensinar a reciprocidade; e e) melhorar a capacidade de reconhecimento (Axelrod, 1986).

Quando o futuro não parece relevante para os envolvidos, a cooperação pode ser mais difícil. Para modificar esse prospecto, os envolvidos precisam vislumbrar maiores retornos na interação futura por meio da cooperação do que os que teriam no presente sem cooperação (Axelrod, 1986; Axelrod e Hodgson, 1994; Riolo et al., 2001). Assim, a frequência ou distribuição no tempo das interações contribui para suscitar a cooperação ou ainda torná-la mais estável (Van Lange et al., 2011). Nesse sentido, a organização, a hierarquização e os sistemas burocráticos desempenham uma função especial, pois concentram e agrupam agentes com interesses comuns para aumentar a frequência das interações. O mesmo efeito é obtido com a realização em etapas de negociações que envolvem interesses conflitantes, avançando em cada ponto discutido em vez de decidir todas as questões de uma única vez. Ao fracionar a interação em etapas, promove-se a estabilidade da cooperação, pois os ganhos que aconteceriam em uma única rodada de negociação são divididos e condicionados à cooperação em rodadas futuras.

As mudanças nos retornos dos agentes objetivam incentivar diretamente a cooperação (Axelrod, 1986). Para isso, não é necessário eliminar a tensão entre os incentivos de curto e de longo prazo a que os atores estão expostos e sobre os quais tomam suas decisões. O necessário é tornar os incentivos de longo prazo mais importantes do que os de curto prazo. Com retornos mais atraentes no longo prazo, a cooperação presente tende a se estabilizar.

Outra maneira de promover a cooperação é ensinar as pessoas a se preocuparem com o bem-estar umas das outras (Axelrod, 1986, 1997; Simon, 1990). A coexistência de altruísmo e egoísmo, porém, pode fazer com que atores egoístas explorem repetidamente os altruístas. Nessa situação, egoístas precisam ser tratados de modo distinto de forma a controlar o custo do altruísmo. Axelrod (1986) sugere que devemos ser altruístas com todos num primeiro momento, mas retaliar posteriormente quem não responde de forma cooperativa. A reciprocidade passa, então, a ser fundamento da cooperação (Axelrod e Hodgson, 1994).

Por isso outra estratégia é ensinar a relevância da reciprocidade, que tem implícito o princípio de sempre cooperar quando o outro também coopera. A desvantagem potencial dessa ação é atrair outros agentes a explorar quem sempre coopera, atingindo também terceiros que dependem dessa interação. Um dos fundamentos da cooperação baseada na reciprocidade é o de não exigir para si mais do que é justo (Camerer e Thaler, 1995). Axelrod (1986) justifica assim ensinar a prática da reciprocidade aos atores para que haja mais interações mutuamente benéficas. Uma retaliação a um ato não cooperativo na mesma intensidade, porém, pode desencadear um contínuo de retaliações recíprocas. Axelrod (1986) sugere então que haja uma única retaliação e em menor intensidade que a primeira ação não colaborativa. Isso ensina o agente não cooperativo que os demais agentes estão dispostos a lhe impor custos 
por não colaborar mas ao mesmo tempo sinaliza a disposição em perdoar e voltar a cooperar (Axelrod e Hodgson, 1994; Gintis et al., 2005; Orbell et al., 1986).

A última forma de promoção da cooperação proposta por Axelrod (1986) envolve aumentar a capacidade de identificarmos os demais atores e as principais características de suas interações passadas. Isso constrói confiança em relação às ações futuras e ajuda a separar com maior precisão os atos não cooperativos e seus respectivos autores. Assim a cooperação ampla não é rompida, mas apenas com o ator não cooperativo. Allan Schmid (2004) acrescenta que o efeito intertemporal da cooperação repetida é a construção do hábito de cooperar e a instituição da confiança entre os agentes, tirando deles a necessidade do dispendioso cálculo racional em cada interação. Se o agente não cooperativo não puder ser claramente identificado, corre-se o risco de perder o benefício coletivo da habituação e da confiança na cooperação.

Os conselhos intermunicipais podem ser colocados sob essas lentes. Eles são um arranjo institucional que congrega entes públicos autônomos de forma a promover entre eles ação cooperativa duradoura (Losada, 2010). No caso específico dos CIS, a cooperação envolve combinar recursos de modo a atender demandas por serviços públicos de média e alta complexidade na área da saúde que não conseguiriam ser atendidas por um município isoladamente (Abrucio et al., 2010). Como espaço institucional, os CIS não têm a priori relações pautadas hierarquicamente pela imposição de um determinado município consorciado sobre os demais (Neves, 2001). As ações planejadas e desenvolvidas são amparadas na concordância da maioria sobre a necessidade de sua realização cooperada. Há, porém, conflitos e divergências que podem atrapalhar a cooperação, pois os municípios têm interesses difusos e os pesos dados às demandas por saúde em cada um deles podem ser distintos. Assim, pode haver desacordo sobre quais são os serviços prioritários, qual forma de gestão aplicar, como distribuir encargos e contribuições, dentre outros. Essas divergências precisam ser superadas para que as ações discutidas possam ser realizadas com esforço mútuo (Dieguez, 2011). O desenvolvimento da cooperação entre os entes consorciados apresenta-se como um mecanismo de enfrentamento e solução desses conflitos, bem como de fortalecimento das bases que suportam o arranjo institucional dos CIS.

\section{Consórcios públicos brasileiros e consórcios intermunicipais de saúde}

A associação entre municípios é prática antiga no Brasil, assim como as leis a seu respeito (Ribeiro, 2007). A mais recente legislação federal sobre os consórcios públicos foi promulgada em 2005 pela Lei ํㅜ 11.107 , e regulamentada em 2007 pelo Decreto $n^{\circ}$ 6.017, oferecendo maior solidez à institucionalidade. Com isso a nova baliza legal potencializou a prática tanto ao lhe dar maior visibilidade quanto ao lhe oferecer parâmetros atualizados.

Até 2011, 2.903 municípios brasileiros (52\% de seu total) participavam de algum consórcio público intermunicipal (tabela 1). Dentre os municípios em consórcios, 2.058 (71\%) são de pequeno porte, ou seja, têm até 20 mil habitantes. Os cinco estados com maior número de municípios consorciados são Minas Gerais com 710 municípios (83\% do total de municípios mineiros), Paraná com 365 (91\% do total), Rio Grande do Sul com 342 (69\% do total), São Paulo com 334 (51\% do total), e Santa Catarina com 252 (86\% do total).

A saúde é a área em que os municípios mais se consorciam: 2.288 municípios participam desse tipo de consórcio público (pouco mais de $41 \%$ do total de municípios). Destes, 
1.743 têm até 20 mil habitantes (tabela 1). A descentralização promovida na área de saúde na década de 1990 levou os entes municipais, em especial os de menor porte, a aglutinarem esforços para enfrentar uma dificuldade comum. Esse movimento se apresenta mais forte nas regiões Sudeste e Sul do que nas Nordeste e Norte. Dos 1.794 municípios do Nordeste, apenas 312 (17\%) participam de algum CIS, dos quais 197 (11\% do total) têm até 20 mil habitantes. Já na região Norte, menos de 6\% de seus 449 municípios participam de um CIS.

Os dados do IBGE (2011) mostram que, quando os consórcios públicos contam com a participação dos municípios e dos estados, as áreas de maior atuação são diferentes do observado quando os consórcios contam somente com municípios. Naquele primeiro grupo ganham importância os consórcios na área de habitação e educação, juntamente com a saúde. Em relação à faixa populacional, há uma maior participação de municípios com 10 a 50 mil habitantes em comparação aos com menos de 10 mil habitantes, que é a faixa populacional de maior concentração de consórcios formados apenas por municípios. Quando os consórcios públicos contam com a participação da União e do respectivo estado, as áreas prioritárias são habitação e educação. Isso parece refletir o interesse das instâncias públicas superiores em direcionar a atuação dos municípios das regiões menos desenvolvidas a empreenderem esforços na direção de tais áreas.

A gradual implantação dos consórcios de saúde ao longo dos anos 1990, por sua vez, sugere a influência de fatores específicos - políticos, institucionais, normativos e organizacionais (Guimarães e Giovanella, 2004). Para Neves e Ribeiro (2006), a maioria dos CIS busca superar as carências na assistência à saúde, com foco em consultas médicas de especialidades, exames de média e alta complexidade, e outras terapias, sem estarem necessariamente subordinados ou vinculados ao controle do governo estadual. Naquele período, o menor comprometimento de governos estaduais no financiamento das políticas de saúde enfraqueceu a formação de sistemas regionais e impulsionou a formação dos CIS, que se apresentaram como alternativa tanto de custeio dos serviços quanto de via para investimentos e disponibilização dos serviços.

Os CIS são, assim, novas institucionalidades no setor público que se afastam do modelo típico da administração direta e que se alinham aos objetivos do SUS de regionalização e hierarquização da oferta de serviços. Eles ajudam na construção de sistemas regionais pactuados, aproximando os serviços prestados à demanda existente. Ademais, as coalizões feitas em torno dos consórcios têm, de modo geral, aumentado a cooperação entre os participantes, mesmo sob o governo de partidos políticos diferentes (Neves e Ribeiro, 2006).

A partir da tabela 2, observa-se que os municípios incrementam sua participação nessa institucionalidade ao mesmo tempo que o contrário acontece com os governos estadual e federal. Os municípios menores, que já participavam amplamente dos CIS, aumentaram sua participação no período. Aqueles com 50 a 100 mil habitantes incrementaram sua participação em 42,7\%, enquanto os com mais de 500 mil habitantes, em 75\%. O número de consórcios públicos que contavam com a participação de municípios e estados caiu pela metade, principalmente entre os municípios nas menores faixas populacionais. E em relação aos consórcios em que a União também participava, a redução seguiu o movimento do âmbito estadual $(-42,8 \%)$, atingindo de forma mais acentuada, porém, os municípios mais populosos. 


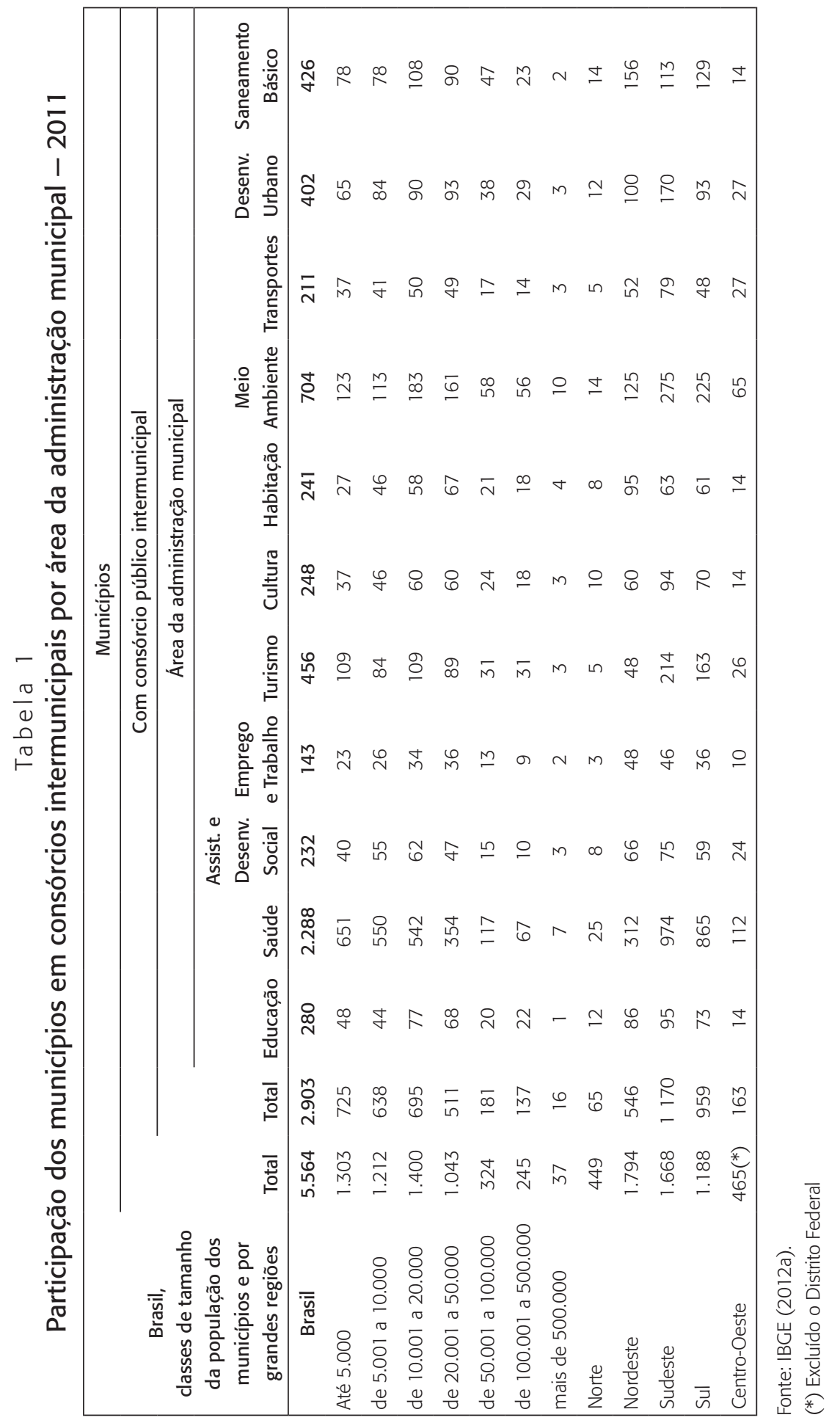

Rev. Adm. Pública - Rio de Janeiro 48(6):1525-1543, nov./dez. 2014 
Tabela 2

Comparação de municípios consorciados na área de saúde, no âmbito municipal, estadual e federal, por faixa de população, Brasil, 2005 e 2011

\begin{tabular}{|c|c|c|c|c|c|c|c|c|c|}
\hline \multirow{3}{*}{$\begin{array}{l}\text { Municípios por } \\
\text { classe de tamanho } \\
\text { da população }\end{array}$} & \multicolumn{3}{|c|}{ Municípios } & \multicolumn{3}{|c|}{ Estados } & \multicolumn{3}{|c|}{ União } \\
\hline & \multirow[b]{2}{*}{2005} & \multicolumn{3}{|c|}{ Variação } & & \multirow[t]{2}{*}{ Variação } & \multirow[b]{2}{*}{2005} & \multirow[b]{2}{*}{2011} & \multirow{2}{*}{$\begin{array}{c}\text { Variação } \\
\%\end{array}$} \\
\hline & & 2011 & $\%$ & 2005 & 2011 & & & & \\
\hline Até 5.000 & 588 & 651 & $10,7 \%$ & 217 & 79 & $-63,6 \%$ & 64 & 42 & $-34,4 \%$ \\
\hline De 5.001 a 10.000 & 497 & 550 & $10,7 \%$ & 225 & 94 & $-58,2 \%$ & 94 & 48 & $-48,9 \%$ \\
\hline De 10.001 a 20.000 & 397 & 542 & $36,5 \%$ & 309 & 174 & $-43,7 \%$ & 96 & 94 & $-2,1 \%$ \\
\hline De 20.001 a 50.000 & 279 & 354 & $26,9 \%$ & 261 & 141 & $-46,0 \%$ & 114 & 72 & $-36,8 \%$ \\
\hline De 50.001 a 100.000 & 82 & 117 & $42,7 \%$ & 89 & 51 & $-42,7 \%$ & 77 & 29 & $-62,3 \%$ \\
\hline De 100.001 a 500.000 & 59 & 67 & $13,6 \%$ & 57 & 42 & $-26,3 \%$ & 91 & 31 & $-65,9 \%$ \\
\hline Mais de 500.000 & 4 & 7 & $75 \%$ & 9 & 3 & $-66,7 \%$ & 22 & 3 & $-86,4 \%$ \\
\hline Total & 1.906 & 2.288 & $20,0 \%$ & 1.167 & 584 & $-50,0 \%$ & 558 & 319 & $-42,8 \%$ \\
\hline
\end{tabular}

Fonte: IBGE $(2006,2012 a)$.

No país, o número de municípios que passaram a integrar algum CIS cresceu $20 \%$ no período. Analisando as grandes regiões, houve reduções nos números de municípios consorciados na região Norte $(-26,5 \%)$ e na Centro-Oeste $(-20,5 \%)$. Nas demais regiões houve aumento de participação, que chegou a $60 \%$ no Nordeste.

O número de CIS em que há participação dos estados caiu drasticamente de 2005 a 2011. Na região Centro-Oeste a redução foi de 90\%, na Norte, de 73\%, e na Sudeste, de 64\%. Em relação à participação da União, somente a região Nordeste registrou aumento das parcerias com os municípios (44\%). Dentre as demais em que houve queda da participação da União, as mais expressivas foram no Centro-Oeste (-90\%) e no Sul (-70,5\%). Essa diminuição no número de consorciamentos com a União pode estar associada à imposição da Lei dos Consórcios Públicos, que determina à União só poder firmar consórcio com os municípios quando o respectivo estado também estiver consorciado. Assim, a redução das parcerias dos estados com os municípios pode ter reverberado sobre a participação da União.

Ao fim, percebe-se que o consorciamento entre os municípios cresceu visivelmente sob o amparo da Lei. É possível que o suporte legal modifique a expectativa de retornos dos agentes públicos, ao mesmo passo que provê aos agentes valores e diretrizes que sirvam para promover a cooperação — duas das três frentes salientadas por Axelrod (1986). Com tal apoio, os agentes públicos têm bases mais firmes para trabalhar na terceira frente, qual seja, vislumbrar a sombra do futuro nas interações municipais.

Vê-se assim que o crescimento no uso dos CIS corresponde ao crescimento do comportamento cooperativo institucionalizado. A partir dessa constatação, passamos ao caso estudado de modo a explorar o entendimento e a motivação de importantes atores dos CIS sobre a prática da cooperação. 


\section{Metodologia}

A partir do trabalho de Axelrod (1986), foi elaborado um questionário direcionado aos diretores dos 22 CIS do estado do Paraná. As associações intermunicipais de saúde (duas no Paraná), com mesma finalidade dos consórcios, mas de natureza jurídica distinta, não integram essa pesquisa. O quadro 1 traz a relação destes CIS e apresenta informações adicionais para melhor contextualização.

\section{Quadro 1}

Consórcios intermunicipais de saúde do estado do Paraná, respectivas sedes, número de municípios associados e população assistida, 2013

\begin{tabular}{|c|c|c|c|}
\hline Consórcios & Sede & $\begin{array}{c}\text { Quantidade } \\
\text { de Municípios } \\
\text { Assistidos }\end{array}$ & População \\
\hline Consórcio Metropolitano de Saúde do Paraná (Comesp) & Curitiba & 21 & 1.260 .363 \\
\hline CIS do Médio Paranapanema (Cismepar) & Londrina & 21 & 871.267 \\
\hline CIS do Setentrião Paranaense (Cisamusep) & Maringá & 30 & 733.404 \\
\hline CIS dos Campos Gerais (Cimsaúde) & Ponta Grossa & 17 & 701.856 \\
\hline CIS do Oeste do Paraná (Cisop) & Cascavel & 25 & 507.385 \\
\hline CIS Costa Oeste do Paraná (Ciscopar) & Toledo & 18 & 358.660 \\
\hline CIS do Vale do Ivaí e Região (Cisvir) & Apucarana & 17 & 346.972 \\
\hline CIS da Região de Campo Mourão (Ciscomcam) & Campo Mourão & 25 & 334.125 \\
\hline CIS do Norte Pioneiro (Cisnorpi) & Jacarezinho & 22 & 278.111 \\
\hline CIS do Litoral do Paraná (Cislipa) & Paranaguá & 7 & 265.392 \\
\hline Consórcio Intermunicipal de Saúde (Cisamunpar) & Paranavaí & 28 & 260.544 \\
\hline CIS do Norte do Paraná (Cisnop) & Cornélio Procópio & 21 & 225.961 \\
\hline CIS do Centro Oeste do Paraná (CIS Centro Oeste) & Guarapuava & 12 & 191.658 \\
\hline CIS Guarapuava/Pinhão (Cisgap) & Guarapuava & 3 & 211.347 \\
\hline Consórcio Intermunicipal de Saúde (Conims) & Pato Branco & 20 & 179.202 \\
\hline CIS do Vale do Iguaçu (Cisvali) & União da Vitória & 9 & 165.299 \\
\hline Consórcio Intermunicipal de Saúde (Cisamerios) & Umuarama & 20 & 155.062 \\
\hline CIS da 22a Regional de Saúde (Cisivaipora) & Ivaiporã & 16 & 139.337 \\
\hline CIS do Iguaçu (Cisi) & Medianeira & 8 & 132.707 \\
\hline CIS do Centro Noroeste do Paraná (Ciscenop) & Cianorte & 10 & 131.371 \\
\hline CIS da Região Centro Sul do Paraná (CIS/Amcespar) & Irati & 8 & 104.755 \\
\hline CIS do Vale do Paranapanema (Cisvap) & Colorado & 8 & 55.182 \\
\hline
\end{tabular}

Fonte: Acispar (2013). 
Os questionários continham perguntas objetivas (com múltipla escolha) e perguntas abertas a serem respondidas de forma descritiva. As questões foram elaboradas de modo a contemplar as sugestões de Axelrod (1986) com relação à promoção e manutenção do comportamento cooperativo. Seu objetivo foi captar a percepção dos diretores sobre como a cooperação se desenvolve entre os municípios dos CIS paranaenses e se a interação ali fortalece a cooperação nos moldes sugeridos por Axelrod (1986, 1997). De modo a conhecer mais da realidade de cada um dos CIS paranaenses, foram acrescentadas questões voltadas à gestão financeira, às fontes de recursos, às facilidades propiciadas pelos consórcios aos municípios e às dificuldades enfrentadas pelos consórcios para cumprirem sua finalidade.

O survey foi realizado junto aos CIS paranaenses com a intermediação da Associação dos Consórcios Intermunicipais do Paraná (Acispar). Os 22 questionários foram enviados ao longo de três meses. O período contemplou consultas telefônicas prévias à Acispar, o envio e o reenvio dos questionários, e a realização de novas consultas telefônicas diretas aos órgãos administrativos dos CIS para solicitar confirmação do recebimento e do envio das respostas. Ao fim do período, obtivemos 10 retornos completos. Outros 10 CIS não retornaram os questionários e não justificaram a negativa quando consultados por telefone. Os dois CIS remanescentes alegaram ter ocorrido uma mudança recente de diretoria e os novos diretores não se sentiram preparados para responder o questionário. Os 10 retornos positivos abarcam um conjunto de 203 municípios assistidos.

\section{Resultados e discussão}

Dentre os 10 CIS respondentes, sete foram instituídos na primeira metade da década de 1990, dois no início da década de 2000 e um em 2010. Isso sugere, como destaca a literatura sobre os CIS, que no Paraná também houve uma resposta positiva ao incentivo para a formação dessa institucionalidade a partir do começo dos anos 1990. No caso do Conims, sediado em Pato Branco (PR), sete dos 20 municípios consorciados são do estado de Santa Catarina. Isso indica que a cooperação e a institucionalização dos CIS dão margem aos municípios para transcender a filiação federativa estadual. Há também a possibilidade de contar com aportes de recursos dos dois estados envolvidos, o que ainda não acontece no caso do Conims.

Entre 2010 e 2012, os valores totais arrecadados pelos 10 CIS paranaenses que compõem a amostra da pesquisa subiram 47,6\% e os valores per capita por eles aplicados subiram 45,3\% (tabela 3). No mesmo período, o gasto per capita do Ministério da Saúde com atenção à saúde em todos os âmbitos cresceu 23\% (Brasil, 2014). Consideremos ainda os valores do Piso de Atendimento Básico (PAB-Fixo), apresentados na última coluna da tabela 3. Eles representam os valores mínimos e máximos per capita transferidos do Fundo Nacional de Saúde aos municípios para financiar despesas com atendimento básico de saúde (Brasil, 2010, 2011, 2012). Ao comparar o crescimento dos valores máximos per capita do PAB-Fixo com o dos gastos per capita realizados pelos CIS da amostra (custeados na maior parte pelos municípios, 
como se verá mais abaixo) entre 2010 e 2012, vê-se que este foi superior àquele em 7\%. Isso aponta para um maior comprometimento financeiro dos municípios para com seus CIS e, por conseguinte, para a importância adquirida pela nova institucionalidade na prestação dos serviços especializados em saúde nos municípios dos CIS respondentes.

Tabela 3

Recursos aplicados pelos CIS respondentes entre 2010 e 2012, população assistida, aplicação per capita, e valores do PAB-Fixo

\begin{tabular}{|cccccc|}
\hline Ano & Valor total em R\$ & Valor médio em R\$ & $\begin{array}{c}\text { População } \\
\text { assistida }\left(^{*}\right)\end{array}$ & $\begin{array}{c}\text { Aplicação per capita ao } \\
\text { ano em R\$ }\end{array}$ & $\begin{array}{c}\text { PAB-Fixo(4) } \\
\text { em R\$ }\end{array}$ \\
\hline 2010 & $76.627 .250,09$ & $7.662 .725,01$ & $4.709 .463^{(1)}$ & 16,27 & 18 \\
2011 & $93.862 .332,69$ & $9.386 .233,27$ & $4.746 .356^{(2)}$ & 19,77 & $18-23$ \\
2012 & $113.116 .909,39$ & $11.311 .690,94$ & $4.782 .579^{(3)}$ & 23,65 & $20-25$ \\
\hline
\end{tabular}

Fonte: Os autores com dados da pesquisa (2013).

(*) Relativa aos municípios que compõem os CIS da amostra da pesquisa

(1) IBGE (2010)

(2) IBGE (2011)

(3) IBGE (2012b)

(4) BRASIL/MS (2010, 2011 e 2012)

Os municípios consorciados da amostra, como esperado, arcam com o maior percentual (62\%) das despesas totais dos CIS. ${ }^{1}$ Eles são seguidos pelo estado (26\%) e pela União (12\%), não havendo envolvimento privado direto em nenhum dos casos respondentes. $\mathrm{O}$ estado do Paraná auxilia nos 10 consórcios pesquisados, enquanto a União repassa recursos para cinco deles. O Consórcio Metropolitano de Saúde do Paraná (Comesp) não conta, por enquanto, com os recursos dos municípios consorciados, sendo suas despesas custeadas pelo estado do Paraná $(68,5 \%)$ e pela União $(31,5 \%)$.

No que se refere aos critérios utilizados pelos CIS para definir as contribuições dos municípios associados, notou-se um esquema predominante. Em cinco dos CIS respondentes, faz-se o rateio de suas despesas fixas de manutenção (pessoal, encargos sociais, materiais etc.) entre os consorciados de forma proporcional ao seu número de habitantes, enquanto as despesas variáveis com os serviços médicos e ambulatoriais são arcadas individualmente pelos municípios conforme suas demandas. Em três deles as despesas fixas e as despesas com serviços médicos e ambulatoriais são divididas entre os municípios proporcionalmente à sua população. Em apenas um caso as despesas fixas são rateadas entre os municípios proporcio-

\footnotetext{
${ }^{1}$ Não discutimos aqui a destinação dos recursos dos CIS. Dados para tal discussão podem ser encontrados no Portal de Transparência de cada consórcio em seus websites.
} 
nalmente à população e há quotas predefinidas de serviços médicos e ambulatoriais para cada um deles. Um único consórcio, o Comesp, não recebe contribuições dos municípios.

Em relação às opções de rateio das despesas fixas dos CIS e da forma de contratação e custeio dos serviços médicos e ambulatoriais especializados, tanto o esquema mais quanto o menos utilizado estabelecem uma quota por uso. Isso é potencialmente menos conflituoso, mas exige maior controle administrativo. Já a segunda opção mais utilizada dificulta a identificação de condutas não cooperativas, exigindo maior atenção do CIS para evitar distorções na utilização dos serviços e que estas prejudiquem a estabilidade da cooperação.

Quanto à finalidade primordial dos CIS, houve também uma resposta predominante. Sete dos diretores responderam que sua finalidade primordial é ser ativo no esforço dos municípios, dos órgãos estaduais e federais para o desenvolvimento de ações que supram as demandas por atendimentos especializados na área de saúde. Para dois dos diretores o consórcio deve contribuir para que os municípios consorciados possam conjuntamente enfrentar e suprir as carências locais e regionais na área de saúde. E no entendimento de um diretor a finalidade do CIS é atuar para suprir as lacunas existentes no SUS que afetam os municípios que integram o consórcio. O quadro 2 mostra a redação das opções tal qual apresentada nos questionários, além da frequência de respostas.

Quadro 2

Principal finalidade do CIS na percepção de seus diretores/gestores

\begin{tabular}{|lc|}
\hline \multicolumn{1}{|c|}{ Finalidade } & Frequência \\
\hline $\begin{array}{l}\text { Desenvolver, em conjunto com os municípios consorciados, com os órgãos estaduais e com os órgãos } \\
\text { federais, ações com a finalidade de suprir as demandas por atendimentos específicos na área de saúde. }\end{array}$ & 7 \\
Contribuir para que os municípios consorciados possam programar e executar ações conjuntas, com o & 2 \\
objetivo de suprir as carências locais e regionais na área de saúde. & 1 \\
Atuar de modo a suprir as lacunas existentes no sistema único de saúde que afetam os municípios & \\
consorciados. & - \\
Atuar como agente facilitador para que os municípios consorciados possam ampliar, no âmbito municipal, & \\
suas ofertas de serviços na área de saúde. & \\
Propiciar espaços para o desenvolvimento de interação entre os municípios consorciados, visando à troca \\
de experiências e recursos técnicos, para melhorar as ações individuais dos municípios na área de saúde.
\end{tabular}

Fonte: Os autores com dados da pesquisa (2013).

A participação dos municípios de forma consorciada pressupõe sua cooperação no intuito de superar conjuntamente os problemas que afetam a todos na área de saúde, desenvolvendo ações de interesse comum. Entretanto, como os municípios consorciados têm históricos distintos na prestação de serviços públicos a seus munícipes, é de se esperar conflitos de interesses na tomada conjunta de decisões com o objetivo de atender necessidades comuns para as quais estão diferentemente equipados. 
Foram então formuladas questões para os diretores dos CIS no intuito de captar sua percepção em relação à atuação e ao posicionamento dos municípios consorciados em situações de forte conflito de interesses na definição das ações a serem desenvolvidas pelos CIS. Os diretores foram indagados sobre a atuação dos CIS nessas situações e se eles entendiam ser central que o consórcio orientasse a discussão de modo a salientar os benefícios futuros da continuidade da cooperação em face dos ganhos presentes em não negociar os seus interesses. Cinco diretores responderam que concordam totalmente e quatro que concordam parcialmente que, em havendo conflito de interesses entre os consorciados, é importante que os consórcios orientem a discussão de modo a salientar o peso do futuro. Um dos diretores respondeu que não discorda nem concorda com esse posicionamento.

As respostas indicam que de maneira geral os diretores entendem que o consórcio deve posicionar-se nas discussões que envolvam interesses conflitantes entre os municípios consorciados. Nota-se que os CIS pesquisados têm legitimidade e autonomia para intervir nas questões conflitantes com o fim de demonstrar que os ganhos futuros têm peso sobre os ganhos presentes e que é necessário reforçar a cooperação presente para que se torne estável. Desse modo os municípios consorciados podem obter continuadamente os retornos esperados no enfretamento dos problemas comuns na área de saúde.

Outra questão nesse sentido envolveu a estratégia de reciprocidade em face do comportamento não colaborativo de forma a coibir sua repetição. Questionou-se se é comum, quando há posicionamento adverso ou não colaborativo de um município, que os outros municípios ajam de forma recíproca, ou seja, que retaliem ou "paguem na mesma moeda" quando os não cooperativos voltam a buscar os benefícios da cooperação no CIS. A percepção de seis dos 10 diretores dos CIS pesquisados é de que não há retaliação pelos municípios nos casos de posicionamento adverso ou não colaborativo de outros municípios consorciados. Para dois deles houve reciprocidade, mas em casos muito pontuais e facilmente identificáveis. Para os outros dois diretores a reciprocidade aparece com mais frequência, mas com menor intensidade do que o fato que lhe deu origem. Assim, as respostas evidenciam que na percepção dos diretores dos CIS pesquisados a atuação da maioria dos municípios consorciados é mais solidamente baseada no princípio de cooperar sempre, mesmo que alguns ocasionalmente não cooperem. A reciprocidade é utilizada nos poucos casos relatados de ação não colaborativa, em intensidade menos que proporcional à mesma, para evitar atuações continuadas que possam explorar os agentes que cooperam incondicionalmente.

O ambiente de interação dos CIS nesta amostra, tal qual percebido por seus diretores, parece de fato propício à cooperação nos moldes indicados por Axelrod (1986). A maioria deles mostra ter uma capacidade de absorver ações não cooperativas sem que seja necessária a retaliação. É possível que os demais elementos salientados, como a presença da sombra do futuro e a fácil identificação das outras partes, inibam a necessidade da retaliação. Podese ainda presumir que a possibilidade de comunicação para além da decisão de cooperar ou não - algo não considerado por Axelrod (1986) — também sirva para evitar a continuidade do conflito. É também interessante notar que nos CIS em que a retaliação ocorreu, ela se deu de forma pontual e menos intensa do que a ação inicial que a provocou. Isso por si 
só se coaduna com o previsto por Axelrod (1986), mas, ainda mais, parece mostrar que o ambiente instituído de interação é capaz de limitar a ação não cooperativa intermitente com estratégia dominante.

Em referência aos conflitos de interesses entre os consorciados, os diretores foram questionados sobre qual a conduta dos CIS para impedir que atrapalhassem a cooperação. As respostas indicam que nessas situações, de maneira geral (para oito dos 10 CIS), busca-se discutir o problema detectado e encontrar a solução pelo consenso entre os municípios consorciados. Em dois casos os diretores indicaram que as decisões das questões controversas foram resolvidas por meio da aprovação da maioria em Assembleia Geral e não pela busca do consenso.

Quando perguntados sobre o que de mais importante o consórcio oferece aos municípios para que decidam atuar em conjunto, os aspectos citados com maior frequência foram: a) oferta de serviços com custo coerente, que possibilita aos municípios ampliarem sua oferta de serviços na área de saúde e suprir suas carências; b) possibilidade de discussão e atuação sobre os problemas regionais da área de saúde; c) respaldo técnico e administrativo na área de saúde; d) maior liberdade para decidir o que é importante para os municípios consorciados.

Os diretores puderam também relatar as dificuldades com as quais se deparam para promover a ação conjunta entre seus municípios. As principais foram: a) atender as demandas distintas dos municípios e conciliar os interesses difusos entre os consorciados; b) lidar com gestores públicos municipais mais preocupados com as questões políticas de seu município do que com a saúde pública com abrangência intermunicipal; c) a falta de estrutura física e de recursos financeiros para as rotinas executivas; d) a distância entre os municípios e entre esses e o CIS.

Buscou-se ainda saber se houve dissolução de algum consórcio ou abandono por parte de algum município. Quanto à primeira questão, não houve dissolução registrada. Quanto à segunda, houve relato de saída sem retorno de apenas quatro municípios (dois no Conims e outros dois no Cisnop). Informações obtidas sobre os motivos das saídas não foram consistentes. Houve um caso de saída com posterior retorno, o do município de Irati (PR), que integrava o Cisamcespar. Em 2010 Irati deixou o CIS e criou o Programa de Especialidades Municipal (PEM), assumindo integralmente a contratação de consultas e exames especializados. A justificativa do prefeito à época foi que sair do consórcio diminuiria custos administrativos e aumentaria a oferta de consultas e exames especializados à população de seu município (Traple, 2011). Os argumentos do prefeito foram contrariados na mesma ocasião pelo chefe da 4a Regional da Saúde do Estado do Paraná e por representantes locais de conselhos de saúde (Traple, 2011). A gestão seguinte decidiu pela volta de Irati ao CIS em 2013 com os argumentos opostos aos da gestão anterior (Irati, 2013; Traple e Zub, 2013).

\section{Considerações finais}

Os consórcios intermunicipais de saúde são institucionalidades que reúnem entes federados autônomos na tentativa de viabilizar serviços que cada um sozinho tem dificuldades de prover. A constituição dos CIS seguiu o incentivo à descentralização promovida pelo SUS na primeira metade dos anos 1990. Os limites geográficos estaduais não são empecilho para que 
os municípios se consorciem e há municípios participantes de mais de um CIS. A evolução dos gastos totais e per capita dos municípios com os CIS em nossa amostra sugere o aumento da importância desta institucionalidade para os municípios.

Sendo um fórum de decisões coletivas, os CIS lidam com conflitos de interesses e negociações que podem fragilizar seu funcionamento. A preservação e a promoção da cooperação tornam-se importantes na sua viscosidade interna. Com base nessa motivação, a pesquisa aqui relatada investigou a percepção dos diretores dos CIS paranaenses sobre a atuação dos municípios consorciados na promoção da cooperação e de que forma os conflitos de interesses são superados na direção da cooperação.

Na percepção da grande maioria dos diretores sobre questões que envolvem conflitos de interesse entre os municípios consorciados, os CIS têm legitimidade e o dever de intervir subsidiando e conduzindo a discussão na direção de um consenso e da manutenção da cooperação entre os municípios. Vê-se assim que nos CIS há a intenção de intervir e orientar os consorciados para que as decisões reforcem a estabilidade da cooperação.

Quanto à utilização da reciprocidade como instrumento para promover a cooperação, a pesquisa indica que a percepção dos diretores dos CIS pesquisados é que a atuação da maioria dos municípios consorciados é a de cooperar sempre, ou seja, não usam a retaliação quando há posicionamento adverso ou não colaborativo de outro município. Apenas dois percebem uma ação regular de reciprocidade, mas a qualificam para casos específicos e não como uma estratégia predominante e generalizada. A relativa estabilidade dos CIS estudados, com baixo número de saídas de consorciados, reforça ainda mais a percepção de que se instituiu a predominância do comportamento cooperativo.

Há, neste estudo, fortes indícios de que os CIS conseguem ser efetivos na promoção da cooperação. Eles reúnem dados e informações sobre os problemas compartilhados, permitindo uma melhor identificação da situação daqueles que interagem, reduzindo a desconfiança entre os mesmos. Além disso, propiciam o espaço institucional para que os municípios possam aumentar a frequência de suas interações, o que auxilia na estabilização da cooperação e na superação de conflitos, como sugere Axelrod (1986).

Como a amostra investigada contou com 10 dos 22 diretores dos CIS paranaenses, de modo não aleatório, a extrapolação dos resultados para outros recortes regionais ou nacionais deve ser muito cautelosa. De todo modo, há aqui evidência de que atores importantes dos CIS enxergam na cooperação a base de seu funcionamento e que ela deve ser ativamente promovida. Isso permite que a lacuna existente em relação à organização regional da oferta de serviços especializados na área de saúde pública seja preenchida, fazendo com que os consórcios

sejam valorizados pelos municípios como uma instituição eficaz na solução dos problemas e das demandas comuns de uma região.

\section{Referências}

ABRUCIO, Fernando; SANO, Hironobu; SYDOW, Cristina. Radiografia do associativismo territorial brasileiro: tendências, desafios e impactos sobre as regiões metropolitanas. In: MAGALHÃES, Fernanda (Ed.). Regiões metropolitanas no Brasil. Washington: BID, 2010. p. 197-234. 
ACISPAR. Associação dos Consórcios de Saúde do Paraná. Consórcios associados. Disponível em: <http://acispar.com.br/Consorcios/consorcios-associados.php>. Acesso em: 5 jan. 2013.

ALLAN SCHMID, A. Conflict and cooperation: institutional and behavioral economics. Oxford: Blackwell, 2004.

AXELROD, Robert [1984]. La evolución de la cooperación: el dilema del prisionero y la teoria de juegos. Madri: Alianza, 1986.

AXELROD, Robert. The complexity of cooperation: agent-based models of competition and collaboration. Princeton: Princeton University Press, 1997.

AXELROD, Robert; HODGSON, Geoffrey. Cooperation, the evolution of. In: HODGSON, Geoffrey; SAMUELS, Warren; TOOL, Marc (Ed.). The Elgar Companion to institutional and evolutionary economics. Aldershot: Edward Elgar, 1994. p. 80-85.

BOWLES, Samuel. Microeconomics: behavior, institutions and evolution. Princeton: Princeton University Press, 2004.

BRASIL. Decreto no 6.017, de 17 de janeiro de 2007. Regulamenta a Lei no 11.107 , de 06 de abril de 2005, que dispõe sobre normas gerais de contratação de consórcios públicos. 2007. Disponível em: <www.planalto.gov.br/ccivil_03/_ato2007-2010/2007/decreto/d6017.htm>. Acesso em: 12 abr. 2014.

BRASIL. Emenda Constitucional no 19, de 04 de junho de 1998. Modifica o regime e dispõe sobre princípios e normas da Administração Pública, servidores e agentes políticos, controle de despesas e finanças públicas e custeio de atividades a cargo do Distrito Federal, e dá outras providências. 1998. Disponível em: <www.planalto.gov.br/ccivil_03/constituicao/Emendas/Emc/emc19.htm>. Acesso em: 05 jan. 2013.

BRASIL. Lei no 11.107, de 06 de abril de 2005. Dispõe sobre normas de contratação de consórcios públicos e dá outras providências. 2005. Disponível em: <www.planalto.gov.br/ccivil_03/_ato20042006/2005/Lei/L11107.htm>. Acesso em: 5 jan. 2013.

BRASIL. Ministério da Saúde. Datasus-Indicadores de recursos: gasto per capita do Ministério da Saúde com atenção à saúde. Disponível em: < http://tabnet.datasus.gov.br/cgi/idb2012/e21.htm> . Acesso em: 23 abr. 2014.

BRASIL. Ministério da Saúde. Portaria nº 953, de 15 de maio de 2012. Define o valor mínimo da parte fixa do Piso de Atenção Básica (PAB), para efeito do cálculo do montante de recursos a ser transferido do Fundo Nacional de Saúde aos Fundos de Saúde dos Municípios e do Distrito Federal, e divulga os valores anuais e mensais da parte fixa do PAB. 2012. Disponível em: <http://bvsms. saude.gov.br/bvs/saudelegis/gm/2012/prt0953_15_05_2012.html>. Acesso em: 12 abr. 2014.

BRASIL. Ministério da Saúde. Portaria no 1.602, de 09 de julho de 2011. Define o valor mínimo da parte fixa do Piso de Atenção Básica (PAB), para efeito do cálculo do montante de recursos a ser transferido do Fundo Nacional de Saúde aos Fundos de Saúde dos Municípios e do Distrito Federal, e divulga os valores anuais e mensais da parte fixa do PAB. 2011. Disponível em: < http://bvsms. saude.gov.br/bvs/saudelegis/gm/2011/prt1602_09_07_2011. html>. Acesso em: 12 abr. 2014. 
BRASIL. Ministério da Saúde. Portaria no 3.170, de 19 de outubro de 2010. Atualiza a base populacional utilizada para o cálculo do montante de recursos do Piso de Atenção Básica - PAB, a ser transferido do Fundo Nacional de Saúde aos Fundos de Saúde dos Municípios e do Distrito Federal, e divulga os valores anuais e mensais da parte fixa do PAB. 2010. Disponível em: <http://bvsms. saude.gov.br/bvs/saudelegis/gm/2010/prt3170_19_10_2010.html>. Acesso em: 12 abr. 2014.

CAMERER, Colin; THALER, Richard. Anomalies: ultimatums, dictators and manners. The Journal of Economic Perspectives, v. 9, n. 2, p. 209-219, 1995.

DIEGUEZ, Rodrigo C. Consórcios Intermunicipais em foco: debate conceitual e construção de quadro metodológico para análise política e institucional. Cadernos de Desenvolvimento, v. 6, n. 9, p. 291319, 2011. Disponível em: <www.centrocelsofurtado.org.br/arquivos/image/201111011233060. CD_edicao9_cmpleto.pdf\#page=291>. Acesso em: 13 abr. 2014.

FONG, Christina et al. Reciprocity and the welfare state. In: GINTIS, Herbert et al. (Ed.). Moral sentiments and material interests: the foundation of cooperation in economic life. Cambridge, MA: The MIT Press, 2005. p. 277-303.

GINTIS, Herbert et al. Moral sentiments, material interests: origins, evidence, and consequences. In: GINTIS, Herbert et al. (Ed.). Moral sentiments and material interests: the foundation of cooperation in economic life. Cambridge, MA: The MIT Press, 2005. p. 3-40.

GUIMARÃES, Luisa; GIOVANELLA, Lígia. Cooperação intergovernamental: os consórcios em saúde de Mato Grosso. Saúde em Debate, v. 28, n. 67, p. 149-158, 2004.

IBGE. Estimativas de população para 1o de julho de 2011. 2011. Disponível em: <www.ibge.gov.br/ home/estatistica/populacao/estimativa2011/estimativa_pop.shtm>. Acesso em: 24 abr. 2013.

IBGE. Estimativas de população para 1o de julho de 2012. 2012b. Disponível em: <www.ibge.gov. br/home/estatistica/populacao/estimativa2012/estimativa_tcu.shtm >. Acesso em: 24 abr. 2013.

IBGE. Pesquisa de informações básicas municipais. Perfil dos municípios brasileiros, gestão 2005. Rio de Janeiro: IBGE, 2006.

IBGE. Pesquisa de informações básicas municipais. Perfil dos municípios brasileiros, gestão 2011. Rio de Janeiro: IBGE, 2012a.

IBGE. Resultado do Censo populacional de 2010. Disponível em: <www.ibge.gov.br/home/estatistica/ populacao/censo2010/resultados_dou/default_resultados_dou.shtm >. Acesso em 10 jan. 2013.

IPEA. Cooperação Federativa: a formação de consórcios públicos no Brasil. In: IPEA. Brasil em desenvolvimento: Estado, planejamento e políticas públicas. Brasília: Ipea, 2010. v. 3, p. 551-564.

IRATI. Odilon anuncia volta de Irati ao Consórcio Intermunicipal de Saúde. 2013. Disponível em: $<$ www.irati.pr.gov.br/internas.php?url=mostra_texto\&id_noticia $=3648>$. Acesso em: 23 set. 2013.

JUNQUEIRA, Ana M. et al. Consórcio intermunicipal de saúde no estado de São Paulo: situação atual. Revista de Administração de Empresas, v. 39, n. 4, p. 85-96, 1999. 
KEOHANE, Robert; OSTROM, Elinor (Ed.). Local commons and global interdependence: heterogeneity and cooperation in two domains. Londres: Sage, 1995.

LIMA, Ana P. G. Os Consórcios Intermunicipais de Saúde e o Sistema Único de Saúde. Cad. Saúde Pública, v. 16, n. 4, p. 985-996, 2000.

LOSADA, Paula R. Potencialidades da cooperação intergovernamental para a gestão das regiões metropolitanas do Brasil. In: MAGALHÃES, Fernanda (Ed.). Regiões metropolitanas no Brasil: um paradoxo de desafios e oportunidade. Washington, D.C: BID, 2010. p. 169-196. Disponível em: <http://idbdocs.iadb.org/wsdocs/getdocument.aspx?docnum=36045064\&gt $>$. Acesso em: 14 abr. 2014.

MULLER, Erildo; GRECO, Marisabel. Avaliação da satisfação dos usuários com os serviços do consórcio intermunicipal de saúde do noroeste do Paraná. Ciência \& Saúde Coletiva, v. 15, n. 3, p. 925-930, 2010.

NEVES, Luiz A. Consórcio Intermunicipal de Saúde da região de Penápolis (SP): elementos de cooperação política. Dissertação (mestrado em saúde pública) - Escola Nacional de Saúde Pública, Fundação Oswaldo Cruz, Rio de Janeiro, 2001. Disponível em: < http://arca.icict.fiocruz.br/bitstream/icict/4945/2/253.pdf>. Acesso em: 12 abr. 2014.

NEVES, Luiz A.; RIBEIRO, José M. Consórcios de saúde: estudo de caso exitoso. Cad. Saúde Pública, v. 22, n. 10, p. 2207-2217, 2006.

NICOLETTO, Sônia C. et al. Consórcios Intermunicipais de Saúde: o caso do Paraná, Brasil. Cad. Saúde Pública, v. 21, n. 1, p. 29-38, 2005.

OLIVEIRA, Vanessa. Municípios cooperando com municípios: relações federativas e consórcios intermunicipais de saúde no estado de São Paulo. São Paulo em Perspectiva, v. 22, n. 1, p. 107-122, 2008.

ORBELL, John; DAWES, Robyn; VAN DE DRAGT, Alphons J. C. Organizing groups for collective action. American Political Science Review, v. 80, n. 4, p. 1171-1185, 1986.

OSTROM, Elinor. Governing the commons: the evolution of institutions for collective action. Cambridge: Cambridge University Press, 1990.

OSTROM, Elinor. Policies that crowd out reciprocity and collective action. In: GINTIS, Herbert et al. (Ed.). Moral sentiments and material interests: the foundation of cooperation in economic life. Cambridge, MA: The MIT Press. 2005. p. 253-276.

PESSALI, Huáscar. Novas institucionalidades: ideias e conceitos orientados à política pública. In: OLIVEIRA, Carlos W.; MAGALHÃES, João C. (Org.). Estrutura produtiva avançada e regionalmente integrada: diagnóstico e políticas de redução das desigualdades regionais. Brasília: IPEA, 2011. v. 5-2, p. 255-272.

RIBEIRO, José M.; COSTA, Nilson da. Regionalização da assistência à saúde no Brasil: os consórcios municipais no Sistema Único de Saúde (SUS). Planejamento e Políticas Públicas, n. 22, p. 173-220, 2000 . 
RIBEIRO, Wladimir. Cooperação federativa e a lei dos consórcios públicos. Brasília: CNM, 2007.

RIOLO, Rick; COHEN, Michael; AXELROD, Robert. Evolution of cooperation without reciprocity. Nature, v. 414, n. 6862, p. 441-443, 2001.

SCHNEIDER, Ana M. Os consórcios intermunicipais de saúde no estado do Rio de Janeiro. Physis: Revista de Saúde Coletiva, v. 11, n. 2, p. 51-66, 2001.

SIMON, Herbert. A mechanism for social selection and successful altruism. Science, v. 250, n. 4988, p. 1665-1668, 1990.

TRAPLE, Marli. Saída de Irati do Consórcio de Saúde ainda gera discussões: tema foi debatido durante a conferência. 2011. Disponível em: <http://radionajua.com.br/noticia/noticias/irati-eregiao/saida-de-irati-do-consorcio-de-saude-ainda-gera-discussoes-tema-foi-debatido-durante-aconferencia/8161/>. Acesso em: 23 set. 2013.

TRAPLE, Marli; ZUB, Rodrigo. Irati retorna ao Consórcio Intermunicipal de Saúde após três anos. 2013. Disponível em: <http://radionajua.com.br/noticia/noticias/irati-e-regiao/irati-retorna-aoconsorcio-intermunicipal-de-saude-apos-tres-anos/19235/>. Acesso em: 23 out. 2013.

VAN LANGE, Paul; KLAPWIJK, Anthon; VAN MUNSTER, Laura. How the shadow of the future might promote cooperation. Group Processes \& Intergroup Relations, v. 14, n. 6, p. 857-870, 2011.

Willson Gerigk é doutorando em políticas públicas na Universidade Federal do Paraná (UFPR) e professor assistente da Universidade Estadual do Centro-Oeste (Unicentro). E-mail: gerigkw@gmail.com.

Huáscar Fialho Pessali é doutor em economia pela University of Hertfordshire e professor associado do departamento de economia da Universidade Federal do Paraná (UFPR). E-mail: pessali@ufpr.br. 